Gut and Liver, Vol. 13, No. 1, January 2019, pp. 93-103

\title{
Treatment Outcome and Renal Safety of 3-Year Tenofovir Disoproxil Fumarate Therapy in Chronic Hepatitis B Patients with Preserved Glomerular Filtration Rate
}

In Suk Min, Chang Hun Lee, Ik Sang Shin, Na Eun Lee, Hong Seon Son, Seung Bum Kim, Seung Young Seo, Seong Hun Kim, Sang Wook Kim, Seung Ok Lee, Soo Teik Lee, and In Hee Kim

Department of Internal Medicine, Research Institute of Clinical Medicine of Chonbuk National University-Biomedical Research Institute of Chonbuk National University Hospital, Chonbuk National University Medical School, Jeonju, Korea

Background/Aims: To investigate the treatment efficacy and renal safety of long-term tenofovir disoproxil fumarate (TDF) therapy in chronic hepatitis $\mathrm{B}(\mathrm{CHB})$ patients with preserved renal function. Methods: The medical records of $919 \mathrm{CHB}$ patients who were treated with TDF therapy were reviewed. All patients had preserved renal function with an estimated glomerular filtration rate (eGFR) of at least $60 \mathrm{~mL} / \mathrm{min} / 1.73$ $\mathrm{m}^{2}$. Results: A total of 426 patients (184 treatment-naïve and 242 treatment-experienced) were included for analysis. A virologic response (VR) was defined as achieving an undetectable serum hepatitis B virus (HBV) DNA level, and the overall VR was $74.9 \%, 86.7 \%$, and $89.4 \%$ at the 1,2 , and 3-year follow-ups, respectively. Achieving a VR was not influenced by previous treatment experience, TDF combination therapy, or antiviral resistance. In a multivariate analysis, being hepatitis $\mathrm{B} e$ antigen positive at baseline and having a serum HBV DNA level $\geq 2,000 \mathrm{IU} / \mathrm{mL}$ at 12 months were associated with lower VR rates during the long-term TDF therapy. The overall renal impairment was $2.9 \%, 1.8 \%$, and $1.7 \%$ at the 1, 2, and 3-year follow-ups, respectively. With regard to renal safety, underlying diabetes mellitus (DM) and an initial eGFR of 60 to $89 \mathrm{~mL} / \mathrm{min} / 1.73 \mathrm{~m}^{2}$ were significant independent predictors of renal impairment. Conclusions: TDF therapy appears to be an effective treatment option for CHB patients with a preserved GFR. However, patients with underlying DM and initial mild renal dysfunction (eGFR, 60 to $89 \mathrm{~mL} / \mathrm{min} / 1.73 \mathrm{~m}^{2}$ ) have an increased risk of renal impairment. (Gut Liver 2019;13:93-103)

Key Words: Antiviral agents; Hepatitis B, chronic; Tenofovir;
Treatment outcome; Renal insufficiency

\section{INTRODUCTION}

Hepatitis B virus (HBV) infection is a global health problem since it is a major cause of chronic hepatitis, liver cirrhosis, and hepatocellular carcinoma (HCC). Despite recent advancements in antiviral therapy with nucleos(t)ide analogues (NA), it is still difficult to completely eliminate the covalently closed circular DNA of HBV. Therefore, the primary goal of the current NA therapy in chronic hepatitis B (CHB) patients is long-term suppression of HBV replication. ${ }^{1}$ However, long-term NA therapy is associated with concerns of drug resistance and toxicity. ${ }^{2,3}$ Initially, the wide use of less potent NAs, which have a low genetic barrier to resistance, was associated with high risk of drug resistance. ${ }^{4}$ Treatment with entecavir (ETV), despite its high genetic barrier, also reported increased risk of resistance ${ }^{5,6}$ Furthermore, although oral NAs are generally well-tolerated by patients and safe to use, its long-term use can cause various adverse effects. ${ }^{7.8}$

Tenofovir disoproxil fumarate (TDF), a nucleotide analogue, was shown to be highly effective in achieving undetectable levels of serum HBV DNA and normal range of alanine aminotransferase (ALT) levels. ${ }^{9} 10$ Sustained viral suppression with TDF treatment over a 5-year period was associated with histological improvement in 87\% of patients and 51\% fibrosis regression. ${ }^{11}$ Treatment with TDF in CHB patients is well tolerated without any significant adverse events and showed high rates of viral suppression without the development of drug resistance in clinical trials. ${ }^{12,13}$ Furthermore, TDF monotherapy or TDF-based

Correspondence to: In Hee Kim

Department of Internal Medicine, Research Institute of Clinical Medicine of Chonbuk National University-Biomedical Research Institute of Chonbuk National University Hospital, Chonbuk National University Medical School, 20 Geonji-ro, Deokjin-gu, Jeonju 54907, Korea

Tel: +82-63-250-1677, Fax: +82-63-254-1609, E-mail: ihkimmd@jbnu.ac.kr

Received on April 25, 2018. Revised on July 2, 2018. Accepted on July 5, 2018. Published online December 14, 2018

pISSN 1976-2283 eISSN 2005-1212 https://doi.org/10.5009/gnl18183

In Suk Min and Chang Hun Lee contributed equally to this work as first authors.

() This is an Open Access article distributed under the terms of the Creative Commons Attribution Non-Commercial License (http://creativecommons.org/licenses/by-nc/4.0) which permits unrestricted non-commercial use, distribution, and reproduction in any medium, provided the original work is properly cited. 
combination therapy was highly effective in achieving longterm viral suppression among patients with previous NA treatment failure. ${ }^{14-18}$ Meanwhile, renal safety is one of the greatest concerns with respect to the long-term administration of TDF in CHB patients, and it is still debatable in clinical real-life data. ${ }^{19-23}$ Recently, EASL guideline recommended that one of the risk factors of renal safety is an estimated glomerular filtration rate (eGFR) $<60 \mathrm{~mL} / \mathrm{min} / 1.73 \mathrm{~m}^{2}$. However, the renal safety of long-term TDF therapy among patients with preserved GFR (eGFR $\geq 60 \mathrm{~mL}$ / $\min / 1.73 \mathrm{~m}^{2}$ ) is unclear.

In Korea, TDF is widely used for naïve CHB patients as well as for those with previous NA experience since it was approved for HBV treatment in 2012. Interestingly, in Korea, a large number of $\mathrm{CHB}$ patients with previous treatment experience has a history of long-term lamivudine/adefovir (LAM-ADV) treatment owing to the domestic insurance policy. Moreover, before approval of TDF therapy, substantial patients treated with ADV resistance were rescued with ETV, but treatment efficacy of ETV was not sufficient. Although Korea is a unique area because treatment-experienced patients are prevalent as compared with other countries, there has been no published real-world data on this issue in Korea until now. In this study, we aimed to investigate the treatment efficacy and safety of long-term TDF therapy for a 3-year period in CHB patients with preserved GFR. We also analyzed the factors associated with virologic response and renal safety during long-term TDF therapy.

\section{MATERIALS AND METHODS}

\section{Study patients}

In this cohort study, we reviewed the medical records of 919 CHB patients who were treated with TDF $300 \mathrm{mg}$ daily between August 2012 to December 2016 at Chonbuk National University Hospital (Jeonju, Republic of Korea). The inclusion criteria were: age $>18$ years, hepatitis B surface antigen (HBsAg) positivity without hepatitis C virus (HCV), HCV, or human immunodeficiency virus co-infection, for more than 6 months, and a minimum follow-up duration of 12 months. We included both treatment-naïve and treatment-experienced patients receiving either TDF monotherapy or TDF combination therapy, that is, TDF in combination with a second NA. Patients with the following conditions at the time of initiation of TDF therapy were excluded: undetectable serum HBV DNA $(<20 \mathrm{IU} / \mathrm{mL})$, serum phosphate level $<2.0 \mathrm{mg} / \mathrm{dL}$, renal impairment, that is, eGFR $<60 \mathrm{~mL} / \mathrm{min} / 1.73 \mathrm{~m}^{2}$, pregnancy, HCC or alpha-fetoprotein (AFP) level >100 ng/mL, and other malignancy. Finally, the remaining 426 patients (184 treatment-naïve and 242 treatmentexperienced) were enrolled for analysis in this study (Fig. 1). This study was conducted in compliance with the World Medical Association Declaration of Helsinki and was approved by the Institutional Review Board of Chonbuk National University Hospital (IRB No. 2015-10-020-002). The written informed consents were obtained.

\section{Laboratory assays and routine follow up examinations}

Serum HBV DNA was quantified by real-time polymerase chain reaction assay using the COBAS Taq-Man HBV quantitative test (Roche Molecular Systems Inc., Branchburg, NJ, USA), which had a lower limit of quantification (20 IU/ $\mathrm{mL}$ ). HBV DNA levels were logarithmically transformed for analysis. The presence of HBV DNA polymerase gene mutations conferring resistance to LAM (rtM204V/I/S, rtL180M), ADV (rtA181T/V, rtN236T), and ETV (rtL180M+rtM204V/ $\mathrm{I} \pm \mathrm{rtI} 169 \mathrm{~T} \pm \mathrm{rtV} 173 \mathrm{~L} \pm \mathrm{rtM} 250 \mathrm{~V} / \mathrm{I} / \mathrm{L} / \mathrm{M}_{ \pm} \mathrm{rtT} 184 \mathrm{~S} / \mathrm{A} / \mathrm{I} / \mathrm{L} / \mathrm{G} / \mathrm{C} /$ $\mathrm{M} \pm \mathrm{rtS} 202 \mathrm{I} / \mathrm{G}$ ) was assessed via Restriction Fragment Mass Polymorphism (RFMP) assay. Serum ALT was measured with an enzymatic assay. Serum HBsAg, antibodies to HBsAg, hepatitis $\mathrm{B}$ e antigen (HBeAg), and antibodies to $\mathrm{HBeAg}$ (anti-HBe) were detected by electrochemiluminescence immunoassay (Roche Diagnostics, Mannheim, Germany). Routine biochemical tests, in-

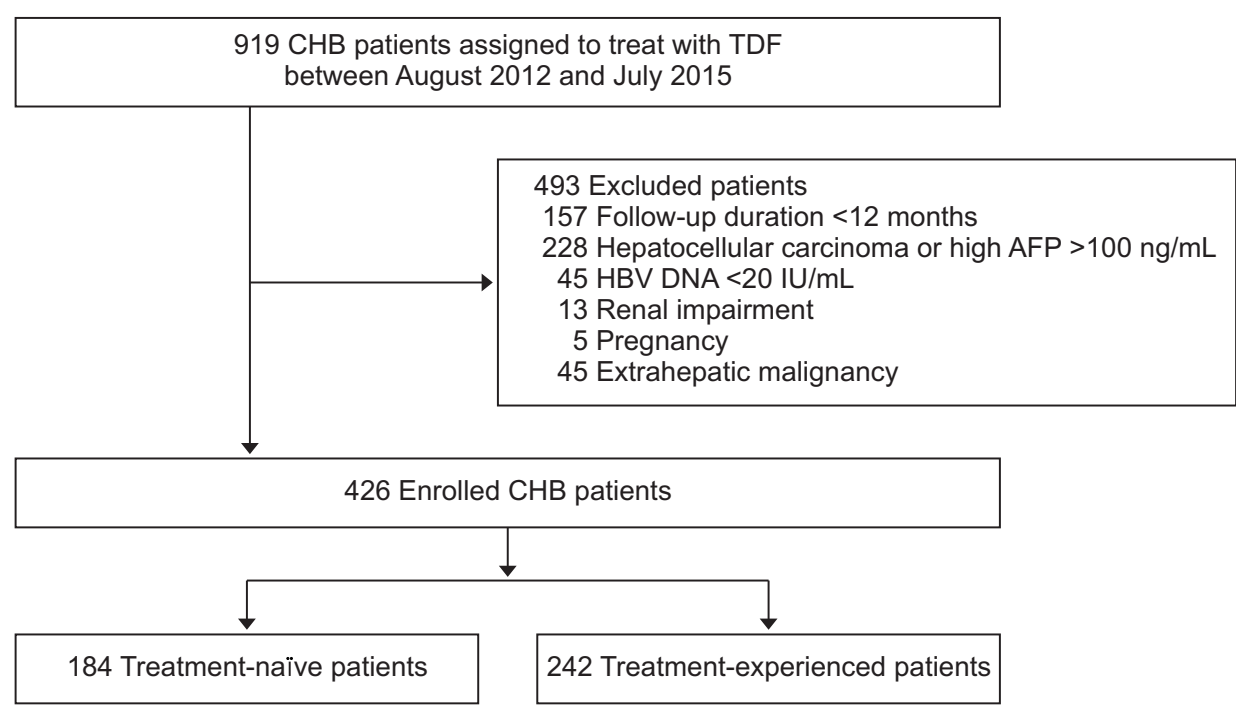

Fig. 1. Flowchart of patient enrollment in this study. CHB, chronic hepatitis B; TDF, tenofovir disoproxil fumarate; AFP, alpha-fetoprotein; HBV, hepatitis B virus. 
cluding serum ALT, creatinine, and phosphorus were performed using a sequential multiple auto-analyzer. During the treatment period, patients were routinely followed up every 1 to 3 months. Serum HBV DNA, ALT, creatinine, eGFR, and phosphorus were assessed routinely every 3 months. $\mathrm{HBeAg} / \mathrm{anti}-\mathrm{HBe}$ and serum AFP level were routinely tested every 6 months. Measurement of eGFR was assessed using the CKD-EPI creatinine Equation. ${ }^{24}$ Ultrasonography or abdominal computed tomography (CT) was performed for HCC surveillance every 6 months.

\section{Definitions}

Virologic response was defined as achieving undetectable serum HBV DNA level $(<20 \mathrm{IU} / \mathrm{mL})$ during the treatment period. Virologic breakthrough was defined as an increase in the serum HBV DNA level of more than $1 \log _{10} \mathrm{IU} / \mathrm{mL}$ from nadir during treatment. $\mathrm{HBeAg}$ seroconversion was defined for $\mathrm{HBeAg}$ positive patients as $\mathrm{HBeAg}$ loss and seroconversion to anti-HBe during treatment. Normalization of ALT was defined as $<40 \mathrm{IU} / \mathrm{L}$. Multidrug resistance (MDR) was defined as a resistance to two or more groups of antiviral drugs; that is, L-nucleoside (LAM, LdT, clevudine), cyclopentane (ETV), or nucleotide analogue (ADV and TDF). Liver cirrhosis was diagnosed by the identification of liver surface nodularity with splenomegaly based on the imaging studies or if clinical findings were suggestive of cirrhotic conditions, such as splenomegaly, thrombocytopenia, varices, and ascites. HCC was diagnosed based on the guidelines proposed by the Korean Liver Cancer Study Group-National Cancer Center. ${ }^{25}$ Renal impairment was defined as elevation of serum creatinine $0.3 \mathrm{mg} / \mathrm{dL}$ above the baseline level or a decrease of eGFR $<60 \mathrm{~mL} / \mathrm{min} / 1.73 \mathrm{~m}^{2}$. Hypophosphatemia was defined as serum phosphorus of less than $2.0 \mathrm{mg} / \mathrm{dL}$.

\section{Statistical analysis}

Data are presented as mean \pm standard deviation or numbers (percentage). We compared continuous or categorical variables between the groups using t-test, chi-square test, or Fisher exact test. Factors associated with virologic response and renal impairment were analyzed by Cox proportional hazard analysis. Cumulative rates of virologic response were evaluated by Kaplan-Meier method and compared using log-rank tests. The results were analyzed using statistical software package SPSS 18.0 (SPSS Inc., Chicago, IL, USA). All tests of significance were two-tailed; p-values $<0.05$ were considered statistically significant.

\section{RESULTS}

\section{Baseline characteristics of study patients}

The baseline characteristics of 426 CHB patients with comparison between treatment-naïve versus treatment-experienced patients are summarized in Table 1 . The mean age of all participants was 48.4 years; 283 (66.4\%) were male, 134 (31.5\%) had liver cirrhosis, 287 (68.0\%) were HBeAg positive. The mean serum HBV DNA level was $4.8 \log _{10} \mathrm{IU} / \mathrm{mL}$. The median duration of TDF based therapy was 28.4 months (range, 12 to 36 months). The cohort included 184 treatment-naïve patients and 242 treatment-experienced patients. Patients in both groups were similar in body mass index, alcohol intake, and frequency of diabetes mellitus (DM). However, treatment-experienced patients were generally older, higher frequency of males, lower rate of cirrhosis, and had significantly lower serum ALT and HBV DNA levels compared with the treatment-naïve patients (Table 1). HBeAg positive patients were more common in the treatment-experienced group. For those in the treatment-naïve group, all were treated with TDF monotherapy; whereas those in the treatment-experienced group, 167 (69.0\%) were treated with TDF monotherapy, and the remaining 75 patients (31.0\%) were treated with TDF combined with another NA therapy. In the treatment-experienced group, the types of previous genotypic resistance included LAM- resistance (R) in 143 (91.7\%), ADV-R in 25 (16.0\%), ETV-R in 30 (19.2\%), and MDR in 43 (17.8\%).

\section{Treatment outcomes of long-term TDF therapy}

The treatment outcomes of TDF therapy are summarized in Table 2. The overall virologic responses were 74.9\%, 86.7\%, and $89.4 \%$ at 1-year, 2-year, and 3-year follow-ups, respectively. It was not significantly different between treatmentnaïve and treatment-experienced patients. The overall rates of HBeAg seroconversion/loss were 9.5\%, 13.7\%, 13.9\% at 1-year, 2-year, and 3-year follow-ups, respectively. It was higher in the treatment-naïve group than in the treatment-experienced group at 1 -year (17.2\% vs 5.2\%, $\mathrm{p}=0.002)$ and 2-year follow-up (27.0\% vs $7.2 \%, \mathrm{p}<0.001)$. The overall rates of serum ALT normalization were $81.4 \%, 84.8 \%$, and $85.2 \%$ at 1-year, 2-year, and 3-year follow-ups, respectively. It was higher in the treatmentnaïve group compared with the treatment-experienced group at 2-year follow-up (91.0\% vs $81.0 \%, \mathrm{p}=0.018$ ). However, it was not significantly different at 1-year and 3-year follow-ups. HBsAg seroconversion occurred in one patient at 1-year and one patient at 2-year follow-ups, respectively. Viral breakthrough occurred in three patients (0.7\%) at the 1-year mark, in four patients (1.2\%) at the 2-year mark, and in three patients (1.3\%) at the 3-year mark. All of them showed poor medication compliance and viral breakthrough resolved after retreatment of TDF. None of them exhibited any resistant or novel mutation to TDF. The overall rates of HCC development were 1.2\%, 1.5\%, 1.7\% at 1-year, 2-year, and 3-year follow-ups, respectively.

\section{Factors associated with virologic response}

In the univariate analysis, age $>60$ years, male sex, body mass index, alcohol intake, presence of DM or cirrhosis, previous treatment experience, ADV-R, MDR, TDF combination therapy, platelet count, and serum ALT level did not influence the achievement of virologic response. Conversely, HBeAg posi- 
Table 1. Baseline Characteristics of Study Subjects

\begin{tabular}{|c|c|c|c|c|}
\hline Characteristics & $\begin{array}{c}\text { Total } \\
(n=426)\end{array}$ & $\begin{array}{l}\text { Treatment-naïve } \\
\qquad(\mathrm{n}=184)\end{array}$ & $\begin{array}{l}\text { Treatment-experienced } \\
\qquad(\mathrm{n}=242)\end{array}$ & $\mathrm{p}$-value \\
\hline Age, yr & $48.4 \pm 11.8$ & $46.9 \pm 12.4$ & $49.5 \pm 11.2$ & 0.03 \\
\hline Male sex & $283(66.4)$ & $112(60.9)$ & $171(70.7)$ & 0.04 \\
\hline BMI, $\mathrm{kg} / \mathrm{m}^{2}$ & $23.6 \pm 3.1$ & $23.6 \pm 3.4$ & $23.6 \pm 2.8$ & 0.99 \\
\hline Alcohol intake & 139 (32.7) & $69(37.5)$ & $70(29.0)$ & 0.07 \\
\hline DM & $23(5.4)$ & $14(7.6)$ & $9(3.7)$ & 0.13 \\
\hline Cirrhosis & $134(31.5)$ & 73 (39.7) & $61(25.2)$ & 0.002 \\
\hline ALT, IU/L & $110.3 \pm 323.4$ & $188.1 \pm 470.1$ & $51.1 \pm 92.0$ & $<0.001$ \\
\hline Creatinine, mg/dL & $0.8 \pm 0.2$ & $0.7 \pm 0.2$ & $0.8 \pm 0.2$ & 0.06 \\
\hline $\mathrm{eGFR}, \mathrm{mL} / \mathrm{min} / 1.73 \mathrm{~m}^{2}$ & $103.4 \pm 14.1$ & $105.0 \pm 15.3$ & $102.2 \pm 13.0$ & 0.05 \\
\hline HBeAg-positive & $287(68.0)$ & $105(57.1)$ & $182(76.5)$ & $<0.001$ \\
\hline HBV DNA, $\log _{10} \mathrm{IU} / \mathrm{mL}$ & $4.8 \pm 2.2$ & $6.2 \pm 1.7$ & $3.8 \pm 1.8$ & $<0.001$ \\
\hline HBV DNA $\geq 8 \log I U / m L$ & $51(12.0)$ & $43(23.4)$ & 8 (3.3) & $<0.001$ \\
\hline TDF therapy & & & & $<0.001$ \\
\hline TDF monotherapy & $351(82.4)$ & $184(100.0)$ & $167(69.0)$ & \\
\hline TDF combination therapy* & $75(17.6)$ & 0 & $75(31.0)$ & \\
\hline Previous NA resistant mutations $^{\dagger}$ & - & - & & - \\
\hline LAM-R & & & $143(91.7)$ & \\
\hline ADV-R & & & $25(16.0)$ & \\
\hline ETV-R & & & $30(19.2)$ & \\
\hline MDR & & & $43(17.8)$ & \\
\hline Follow-up duration, mo & $28.4(12-36)$ & $25.8(12-36)$ & $30.4(12-36)$ & $<0.001$ \\
\hline
\end{tabular}

Data are presented as mean \pm SD, number (\%), or median (range).

BMI, body mass index; DM, diabetes mellitus; ALT, alanine aminotransferase; eGFR, estimated glomerular filtration rate; HBeAg, hepatitis B e antigen; HBV, hepatitis B virus; TDF, tenofovir disoproxil fumarate; NAs, nucleos(t)ide analogues; LAM-R, lamivudine resistance; ADV-R, adefovirresistance; ETV-R, entecavir-resistance; MDR, multidrug resistance.

*TDF combined with other NAs; ${ }^{\dagger} \mathrm{LAM}-\mathrm{R}$ mutations include rtM204V/I \pm rtL180M, ADV-R mutations include rtA181T/V and rtN236T/V, and ETVR mutations include rtT184, rtI169, and rtS202.

tivity, serum HBV DNA level at baseline, serum HBV DNA level $\geq 8 \log _{10} \mathrm{IU} / \mathrm{mL}$ at baseline, and serum HBV DNA level $\geq 2,000$ $\mathrm{IU} / \mathrm{mL}$ at 12 months were significantly associated with virologic response during long-term TDF therapy (Table 3). In the multivariate analysis, $\mathrm{HBeAg}$-positive (hazard ratio [HR], 0.727; 95\% CI, 0.58 to $0.91 ; \mathrm{p}=0.006$ ) and serum HBV DNA level $\geq 2,000$ $\mathrm{IU} / \mathrm{mL}$ at 12 months (HR, 0.271; 95\% CI, 0.13 to 0.58 ; $\mathrm{p}=0.001$ ) were significant independent factors associated with lower rate of virologic response (Table 3).

The overall cumulative rates of virologic response are shown in Fig. 2. The cumulative rates of virologic response in accordance with the subgroups are shown in Fig. 3. The cumulative rates of virologic response was not significantly different between the subgroups, such as treatment-naïve versus treatment experienced, TDF monotherapy versus TDF combination therapy, no resistance versus LAM/CLV/LdT-R versus ADV-R versus ETV-R versus MDR patients (Fig. 3A, B, D). However, those who were $\mathrm{HBeAg}$-positive at baseline, $\mathrm{HBV}$ DNA $\geq 8 \log 10 \mathrm{U} / \mathrm{mL}$ at baseline, and serum HBV DNA level $\geq 2,000 \mathrm{IU} / \mathrm{mL}$ at 12 months showed significantly lower rates of virologic response during long-term TDF therapy (Fig. 3C, E, F).

\section{Renal safety during long-term TDF therapy}

Renal safety profiles during the long-term TDF therapy are summarized in Table 4. The mean serum creatinine level and eGFR were not significantly altered during the follow-up period. Among the total study population, the incidence of renal impairment was seen in 12 out of 411 (2.9\%) at 1-year, six out of 342 $(1.8 \%)$ at 2-year, and four out of $229(1.7 \%)$ at 3-year followup time points. It was not significantly different between the treatment-naïve and treatment-experienced group (3.4\% vs 2.6\% at 1 -year, $1.5 \%$ vs $1.9 \%$ at 2-year, and $1.3 \%$ vs $2.0 \%$ at 3 -year follow-ups, respectively). There were two patients at 1-year and one patient at 3-year of follow-up who modified their TDF dose due to reduced GFR and all of them were resolved without treatment interruption. Although four patients recovered their renal functions during follow-up periods, the others maintained gradually decreased renal function. In addition, patients with renal impairment showed rapid decline of GFR as $-34.2 \pm 11.7$, $-28.2 \pm 12.5$, and $-38.4 \pm 7.1 \mathrm{~mL} / \mathrm{min} / 1.73 \mathrm{~m}^{2}$ at 1-year, 2-year, 
Table 2. Treatment Outcomes of Long-Term TDF Therapy in the Treatment-Naïve and Treatment-Experienced CHB Groups

\begin{tabular}{|c|c|c|c|c|}
\hline \multicolumn{2}{|c|}{ Characteristics } & \multirow{2}{*}{$\begin{array}{c}1 \text { Year }(\mathrm{n}=426) \\
319 / 426(74.9)\end{array}$} & \multirow{2}{*}{$\begin{array}{c}2 \text { Years }(\mathrm{n}=347) \\
301 / 347(86.7)\end{array}$} & \multirow{2}{*}{$\begin{array}{c}3 \text { Years }(\mathrm{n}=236) \\
211 / 236(89.4)\end{array}$} \\
\hline Virologic response & Total & & & \\
\hline & Naïve & $133 / 184(72.3)$ & 119/134 (88.8) & $66 / 78(84.6)$ \\
\hline & Experienced & $186 / 242$ (76.9) & $182 / 213(85.4)$ & $145 / 158(91.8)$ \\
\hline & p-value & 0.334 & 0.462 & 0.145 \\
\hline \multirow[t]{4}{*}{ HBeAg seroconversion/loss } & Total & $26 / 273(9.5)$ & $31 / 227$ (13.7) & 22/151 (13.9) \\
\hline & Naïve & 17/99 (17.2) & 20/74 (27.0) & $9 / 40(22.5)$ \\
\hline & Experienced & $9 / 174(5.2)$ & $11 / 153(7.2)$ & 13/109 (11.9) \\
\hline & p-value & 0.002 & $<0.001$ & 0.176 \\
\hline \multirow[t]{4}{*}{ ALT normalization } & Total & $345 / 424(81.4)$ & $291 / 343(84.8)$ & 196/230 (85.2) \\
\hline & Naïve & $152 / 182(83.5)$ & $121 / 133$ (91.0) & $64 / 77(83.1)$ \\
\hline & Experienced & 193/242 (79.8) & 170/210 (81.0) & 132/153 (86.3) \\
\hline & p-value & 0.324 & 0.018 & 0.660 \\
\hline \multirow[t]{4}{*}{ Virologic breakthrough } & Total & $3 / 426(0.7)$ & $4 / 347(1.2)$ & $3 / 236(1.3)$ \\
\hline & Naïve & $0 / 184(0.0)$ & $1 / 134(0.7)$ & $3 / 78(3.8)$ \\
\hline & Experienced & $3 / 242(1.2)$ & 3/213 (1.4) & 0/158 (0.0) \\
\hline & p-value & 0.352 & 0.963 & 0.062 \\
\hline \multirow[t]{4}{*}{ Genotypic resistance } & Total & 0 & 0 & 0 \\
\hline & Naïve & 0 & 0 & 0 \\
\hline & Experienced & 0 & 0 & 0 \\
\hline & p-value & - & - & - \\
\hline
\end{tabular}

Data are presented as number/number (\%).

TDF, tenofovir disoproxil fumarate; CHB, chronic hepatitis B; HBeAg, hepatitis B e antigen; ALT, alanine aminotransferase.

Table 3. Factors Associated with Virologic Response

\begin{tabular}{|c|c|c|c|c|c|c|}
\hline \multirow{2}{*}{ Characteristics } & \multicolumn{3}{|c|}{ Univariate analysis } & \multicolumn{3}{|c|}{ Multivariate analysis } \\
\hline & p-value & HR & $95 \% \mathrm{CI}$ & p-value & $\mathrm{HR}$ & $95 \% \mathrm{CI}$ \\
\hline Age $>60 \mathrm{yr}$ & 0.706 & 0.949 & $0.723-1.246$ & & & \\
\hline Male sex & 0.620 & 0.948 & $0.768-1.171$ & & & \\
\hline BMI & 0.751 & 1.007 & $0.963-1.054$ & & & \\
\hline Alcohol intake & 0.099 & 0.831 & $0.667-1.035$ & & & \\
\hline DM & 0.878 & 0.965 & $0.615-1.514$ & & & \\
\hline Cirrhosis & 0.242 & 1.138 & $0.917-1.412$ & & & \\
\hline Treatment-experienced vs naïve & 0.493 & 1.074 & $0.876-1.317$ & & & \\
\hline ADV resistance & 0.809 & 0.948 & $0.617-1.459$ & & & \\
\hline Multi-drug resistance & 0.596 & 0.913 & $0.653-1.277$ & & & \\
\hline TDF combination therapy vs TDF monotherapy & 0.358 & 0.881 & $0.673-1.154$ & & & \\
\hline Platelets, $\times 10^{6} / \mathrm{mm}^{3}$ & 0.990 & 1.000 & $0.999-1.001$ & & & \\
\hline ALT, IU/L & 0.767 & 1.000 & $1.000-1.000$ & & & \\
\hline HBeAg positive vs negative & 0.001 & 0.684 & $0.549-0.851$ & 0.006 & 0.727 & $0.580-0.912$ \\
\hline HBV DNA, IU/mL, baseline & 0.003 & 1.000 & $1.000-1.000$ & 0.367 & 1.000 & $1.000-1.000$ \\
\hline HBV DNA $\geq 8 \log _{10} \mathrm{U} / \mathrm{mL}$ at baseline vs $<8 \log _{10} \mathrm{U} / \mathrm{mL}$ & 0.007 & 0.622 & $0.440-0.880$ & 0.760 & 1.197 & $0.377-3.797$ \\
\hline $\mathrm{HBV}$ DNA $\geq 2,000 \mathrm{IU} / \mathrm{mL}$ at $12 \mathrm{mo}$ vs $<2,000 \mathrm{IU} / \mathrm{mL}$ & $<0.001$ & 0.256 & $0.121-0.545$ & 0.001 & 0.271 & $0.127-0.579$ \\
\hline
\end{tabular}

HR, hazard ratio; CI, confidence interval; BMI, body mass index; DM, diabetes mellitus; ADV, adefovir; TDF, tenofovir disoproxil fumarate; ALT, alanine aminotransferase; $\mathrm{HBeAg}$, hepatitis B e antigen; $\mathrm{HBV}$, hepatitis B virus. 
A

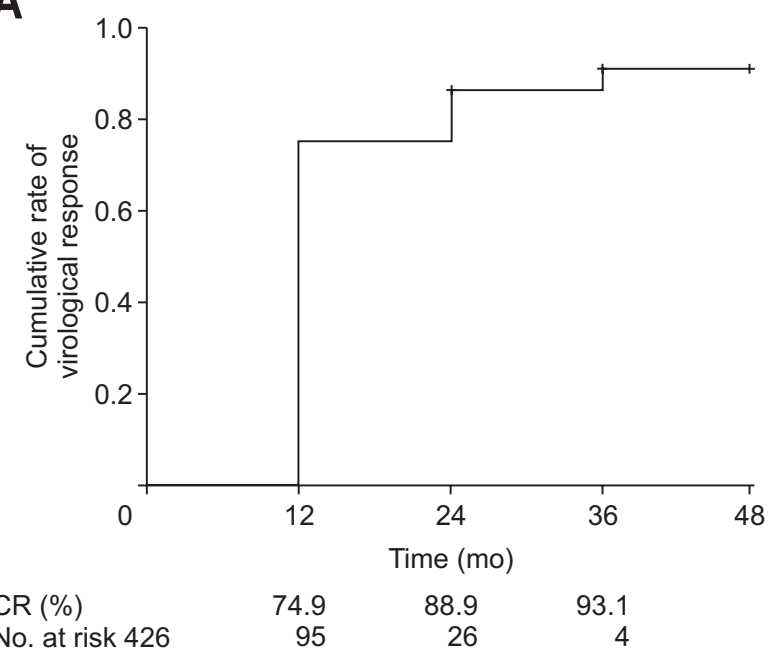

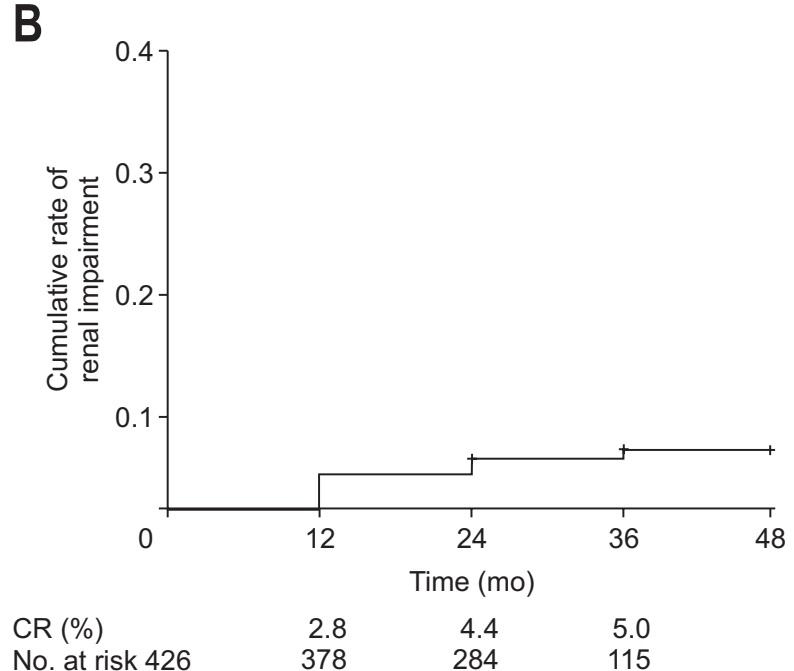

Fig. 2. Cumulative rates (CR) of virologic response (A) and renal impairment (B) among all chronic hepatitis B patients.

A

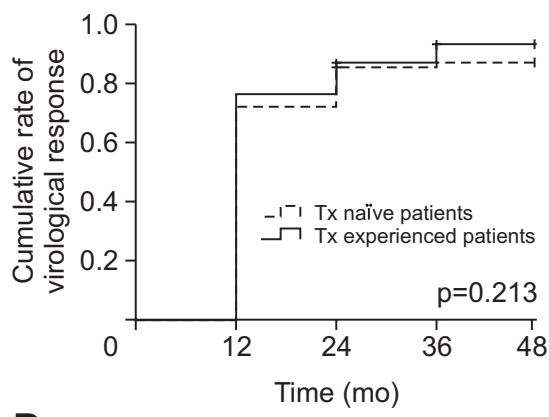

D

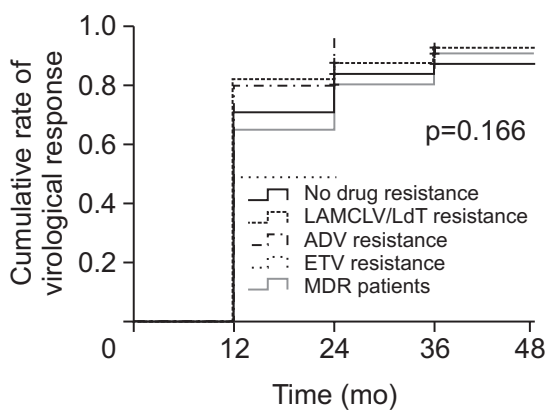

B

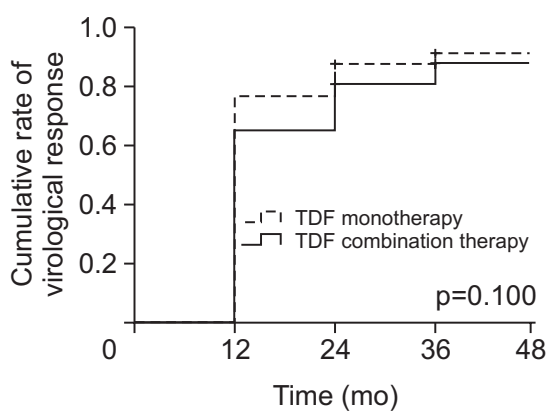

E

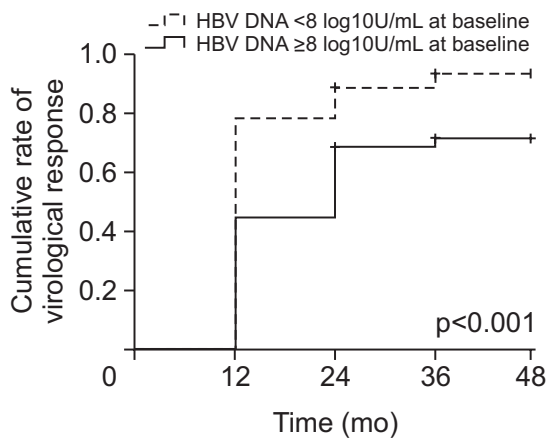

C

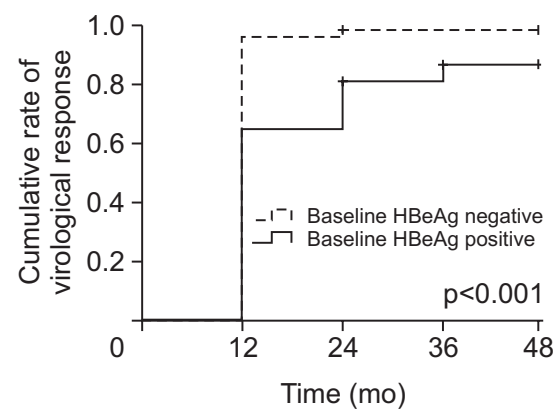

F

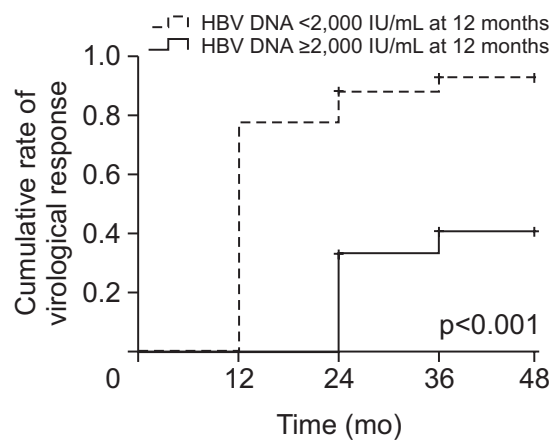

Fig. 3. Cumulative rates (CR) of virologic response (serum HBV DNA level $<20 \mathrm{IU} / \mathrm{mL}$ ) in the subgroup analysis. (A) Treatment-naïve vs treatmentexperienced patients. (B) TDF-monotherapy vs TDF-combination therapy patients. (C) HBeAg-negative vs HBeAg-positive patients. (D) No resistance vs LAM/CLV/LdT-resistance vs ADV-resistance vs ETV-resistance vs MDR. (E) HBV DNA $<8 \log 10 \mathrm{U} / \mathrm{mL}$ at baseline vs HBV DNA $\geq 8$ log 10 $\mathrm{U} / \mathrm{mL}$ at baseline. (F) HBV DNA <2,000 IU/mL at 12 months vs HBV DNA $\geq 2,000 \mathrm{IU} / \mathrm{mL}$ at 12 months.

Tx, treatment; HBV, hepatitis B virus; TDF, tenofovir disoproxil fumarate; HBeAg, hepatitis B e antigen; LAM, lamivudine; CLV, clevudine; LdT, telbivudine; ADV, adefovir; ETV, entecavir; MDR, multidrug resistance.

and 3-year follow-ups, respectively. During the 3 years of follow-up, two patients were expired. One patient who had been maintained TDF monotherapy advanced to the hepatorenal syndrome. The other patient was not a renal impairment-related death which was variceal bleeding case underlying HCC. The incidence of hypophosphatemia $(<2.0 \mathrm{mg} / \mathrm{dL})$ was 0 out of 359 $(0.0 \%)$ at 1-year, three out of $294(1.0 \%)$ at 2-year, and one out of $191(0.5 \%)$ at 3-year follow-ups. 
Table 4. Renal Safety during Long-Term Tenofovir Disoproxil Fumarate Therapy

\begin{tabular}{|c|c|c|c|c|}
\hline \multicolumn{2}{|l|}{ Characteristics } & \multirow{2}{*}{$\begin{array}{c}1 \text { Year }(n=426) \\
0.0 \pm 0.1\end{array}$} & \multirow{2}{*}{$\begin{array}{c}2 \text { Years }(\mathrm{n}=347) \\
-0.0 \pm 0.1\end{array}$} & \multirow{2}{*}{$\begin{array}{c}3 \text { Years }(\mathrm{n}=236) \\
-0.0 \pm 0.1\end{array}$} \\
\hline Mean serum creatinine level changes, $\mathrm{mg} / \mathrm{dL}$ & Total & & & \\
\hline & Naïve & $0.0 \pm 0.1$ & $-0.0 \pm 0.1$ & $-0.0 \pm 0.1$ \\
\hline & Experienced & $0.0 \pm 0.1$ & $-0.0 \pm 0.1$ & $-0.0 \pm 0.1$ \\
\hline & p-value & 0.739 & 0.380 & 0.511 \\
\hline \multirow[t]{4}{*}{ Mean eGFR changes, $\mathrm{mL} / \mathrm{min} / 1.73 \mathrm{~m}^{2}$} & Total & $-1.7 \pm 11.1$ & $-0.4 \pm 10.0$ & $-1.5 \pm 10.3$ \\
\hline & Naïve & $-1.4 \pm 11.6$ & $-0.9 \pm 11.0$ & $-0.7 \pm 10.5$ \\
\hline & Experienced & $-2.0 \pm 10.7$ & $-0.1 \pm 9.3$ & $-1.9 \pm 10.2$ \\
\hline & p-value & 0.621 & 0.508 & 0.401 \\
\hline \multirow[t]{4}{*}{ Renal impairment } & Total & $12 / 411(2.9)$ & $6 / 342(1.8)$ & $4 / 229(1.7)$ \\
\hline & Naïve & $6 / 179(3.4)$ & $2 / 132(1.5)$ & $1 / 76(1.3)$ \\
\hline & Experienced & $6 / 232(2.6)$ & $4 / 210(1.9)$ & $3 / 153(2.0)$ \\
\hline & p-value & 0.872 & 1.000 & 1.000 \\
\hline \multirow[t]{4}{*}{ Mean serum phosphorus level changes, mg/dL } & Total & $-0.0 \pm 0.6$ & $-0.0 \pm 0.6$ & $-0.1 \pm 0.5$ \\
\hline & Naïve & $-0.0 \pm 0.6$ & $-0.0 \pm 0.6$ & $-0.1 \pm 0.6$ \\
\hline & Experienced & $-0.0 \pm 0.5$ & $-0.1 \pm 0.5$ & $-0.0 \pm 0.5$ \\
\hline & p-value & 0.633 & 0.729 & 0.492 \\
\hline \multirow[t]{4}{*}{ Hypophosphatemia } & Total & $0 / 359(0.0)$ & $3 / 294(1.0)$ & $1 / 191(0.5)$ \\
\hline & Naïve & $0 / 169(0.0)$ & $0 / 125(0.0)$ & $1 / 72(1.4)$ \\
\hline & Experienced & $0 / 190(0.0)$ & $3 / 169(1.8)$ & $0 / 119(0.0)$ \\
\hline & $\mathrm{p}$-value & - & 0.363 & 0.799 \\
\hline
\end{tabular}

Data are presented as mean \pm SD or number/number (\%). eGFR, estimated glomerular filtration rate.

\section{Factors associated with renal impairment}

In the univariate analysis, age $>60$ years, DM, and eGFR 60 to $89 \mathrm{~mL} / \mathrm{min} / 1.73 \mathrm{~m}^{2}$ were significantly associated with renal impairment during long-term TDF therapy (Table 5). Multivariate analysis showed underlying DM (HR, 4.803; 95\% CI, 1.55 to 14.87; $\mathrm{p}=0.007)$ and eGFR 60 to $89 \mathrm{~mL} / \mathrm{min} / 1.73 \mathrm{~m}^{2}$ (HR, 3.119; 95\% CI, 1.179 to $8.32 ; \mathrm{p}=0.023$ ) as independent significant factors associated with renal impairment (Table 5).

The overall cumulative rates of renal impairment are shown in Fig. 2. The cumulative rates of renal impairment in accordance with the subgroups are shown in Fig. 4. Patients who had underlying DM and represented initial mildly decreased renal function (eGFR 60 to $89 \mathrm{~mL} / \mathrm{min} / 1.73 \mathrm{~m}^{2}$ ) showed significantly higher rates of renal impairment during long-term TDF therapy.

\section{DISCUSSION}

Antiviral therapy for CHB is the most widely used strategy for improving survival by preventing progression to cirrhosis and HCC. Because HBsAg seroconversion rate is very low, long-term use of antiviral agents is necessary for sustained viral suppression. Although TDF showed a high antiviral efficacy in a longterm registration trial, treatment strategy and efficacy may be influenced by various factors of individual in the real world. ${ }^{26,27}$
Therefore, real-life data reflecting the heterogeneity of patients treated with antiviral therapy depending on the various conditions, and factors associated with virological response and adverse events, are needed to be elucidated.

In this study, TDF based therapy was highly effective for CHB patients for up to 3 years. In the multivariate analysis, HBeAgpositive and serum HBV DNA level $\geq 2,000 \mathrm{IU} / \mathrm{mL}$ at 12 months were independent factors associated with lower virologic response. However, the treatment outcomes were not significantly affected by treatment experience, TDF combination therapy, and previous antiviral resistance. This study included CHB patients with preserved renal function (eGFR $\geq 60 \mathrm{~mL} / \mathrm{min} / 1.73 \mathrm{~m}^{2}$ ) at baseline and the incidence of renal impairment was quite low. The presence of DM and eGFR 60 to $89 \mathrm{~mL} / \mathrm{min} / 1.73 \mathrm{~m}^{2}$ were independent factors associated with renal impairment.

Prior antiviral treatment experience is one of the important factors affecting drug efficacy because experienced individuals may likely have developed drug resistance, genetic mutation, or virologic non-response. Before the emergence of TDF, many kinds of antiviral drugs, including ETV, have relatively high frequency of drug resistance, although they may be used in combination. Some previous studies demonstrated that previous ADV-experienced patients have inferior efficacy of TDF compared with NA-naïve patients. ${ }^{28}$ Some reported TDF monotherapy showed superior efficacy compared with LMV plus ADV 
Table 5. Factors Associated with Renal Impairment

\begin{tabular}{|c|c|c|c|c|c|c|}
\hline \multirow{2}{*}{ Characteristics } & \multicolumn{3}{|c|}{ Univariate analysis } & \multicolumn{3}{|c|}{ Multivariate analysis } \\
\hline & p-value & $\mathrm{HR}$ & $95 \% \mathrm{CI}$ & $\mathrm{p}$-value & $\mathrm{HR}$ & $95 \% \mathrm{CI}$ \\
\hline Age $>60 \mathrm{yr}$ & 0.032 & 2.728 & $1.089-6.838$ & 0.322 & 1.649 & $0.612-4.444$ \\
\hline Male sex & 0.715 & 1.195 & $0.459-3.110$ & & & \\
\hline BMI & 0.748 & 1.027 & $0.874-1.207$ & & & \\
\hline Alcohol intake & 0.068 & 3.139 & $0.920-10.714$ & & & \\
\hline DM & 0.006 & 4.712 & $1.574-14.106$ & 0.006 & 4.790 & $1.552-14.784$ \\
\hline Cirrhosis & 0.184 & 1.817 & $0.753-4.387$ & & & \\
\hline Treatment-experienced vs naïve & 0.834 & 0.910 & $0.377-2.197$ & & & \\
\hline ADV experienced & 0.858 & 0.905 & $0.302-2.707$ & & & \\
\hline TDF combination therapy vs TDF monotherapy & 0.166 & 0.241 & $0.032-1.803$ & & & \\
\hline Platelets, $\times 10^{6} / \mathrm{mm}^{3}$ & 0.090 & 0.994 & $0.987-1.001$ & & & \\
\hline ALT, IU/L & 0.686 & 0.999 & $0.997-1.002$ & & & \\
\hline Initial eGFR $60-89, \mathrm{~mL} / \mathrm{min} / 1.73 \mathrm{~m}^{2}$ & 0.005 & 3.680 & $1.468-9.224$ & 0.014 & 3.413 & $1.276-9.131$ \\
\hline HBV DNA at baseline, IU/mL & 0.224 & 1.000 & $1.000-1.000$ & & & \\
\hline
\end{tabular}

HR, hazard ratio; CI, confidence interval; BMI, body mass index; DM, diabetes mellitus; ADV, adefovir; TDF, tenofovir disoproxil fumarate; ALT, alanine aminotransferase; eGFR, estimated glomerular filtration rate; HBV, hepatitis B virus.
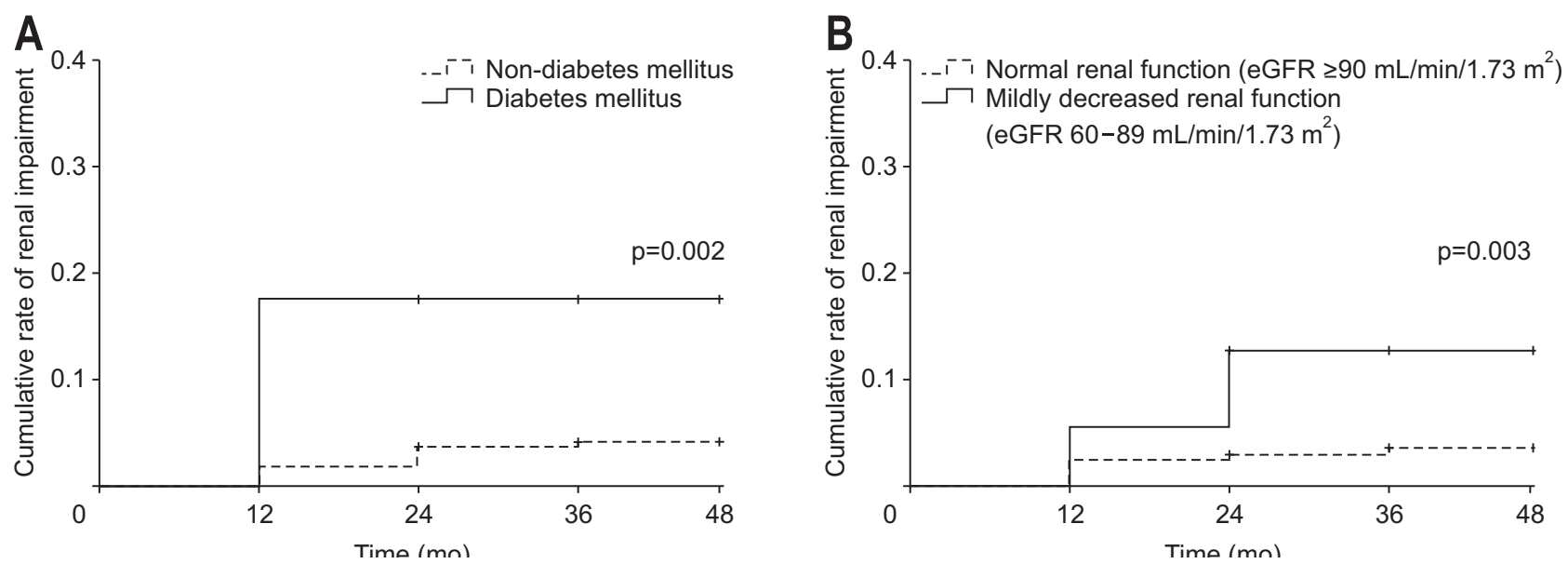

Fig. 4. Cumulative rate of renal impairment in the subgroup analysis. (A) Patients with vs without diabetes mellitus. (B) Patients with normal renal function (eGFR $\geq 90 \mathrm{~mL} / \mathrm{min} / 1.73 \mathrm{~m}^{2}$ ) vs patients with mildly decreased renal function (eGFR $60-89 \mathrm{~mL} / \mathrm{min} / 1.73 \mathrm{~m}^{2}$ ).

eGFR, estimated glomerular filtration rate.

or ETV plus ADV in LAM-R CHB patients. ${ }^{29,30}$ As a combination strategy, regarding previous reports, the efficacy of TDF mono- and combination treatments was similar, ${ }^{31}$ and TDF-ETV combination therapy revealed a high rate of achieving virologic suppression regardless of prior treatment experience without resistance. $^{32}$

Regarding our data, both treatment-naïve and treatmentexperienced groups showed a high frequency of virologic response, ALT normalization, and low virologic breakthrough without statistically significant difference in comparison of these two groups. The difference among them was observed with respect to HBeAg loss/seroconversion at 1-year and 2-year follow-up time points. Prior exposure to antiviral therapy, as well as the development of resistance may influence the results. When we review the data, there were only one patient in the treatment-experienced group who showed HBeAg seroconversion among the 31 patients with multi-drug resistance. In the current study, viral breakthrough occurred in 10 patients during the follow-up duration. We review the data of individuals and found that all of them showed non-compliance with antiviral drugs and viral breakthrough resolved after retreatment of TDF. Similarly, in other studies, viral breakthroughs occurred infrequently and were associated with non-compliance with antiviral drugs. ${ }^{33-35}$ In our study, none of them exhibited any resistance or novel mutation to TDF.

In Korea, LMV-ADV therapy was a treatment option for pa- 
tients with LMV-R. Given the similarity between TDF and ADV, there was a concern about the resistance and inferior treatment response of TDF in ADV-experienced CHB patients, especially who had ADV-R mutations. ${ }^{16}$ In the present study, when we reviewed the virologic response only in ADV-experienced patients $(\mathrm{n}=91)$, virologic response was $80.2 \%, 89.3 \%$, and 93.8\% at 1-year, 2-year, and 3-year follow-ups, respectively. The result was similar or slightly higher compared with the overall treatment experienced patients. Our data suggest that the use of TDF is highly effective regardless of previous ADV exposure.

Sustained virologic response is one of the most important parameters that reflect the treatment response and is crucial to the prevention of the progression of $\mathrm{CHB}$ to cirrhosis, HCC, and liver complication-related deaths. As aforementioned, prior antiviral treatment experience, drug combination therapy, and drug resistance may influence the virologic response. However, cumulative virologic response was not affected with respect to such factors in comparison in this study. Our data suggests that baseline HBeAg positive and HBV DNA levels at 12 months can predict the efficacy of long-term TDF treatment. In previous clinical trials of long-term TDF therapy, participants were separated with regard to HBeAg positivity and, although longterm cumulative virologic response was similar between the two groups, the virologic response rate in early stages was relatively lower in HBeAg-positive patients. ${ }^{27}$ In one previous study, more than $70 \%$ of the study cohort with antiviral resistance showed HBeAg positivity. ${ }^{36}$ Regarding the relationship between HBV DNA level and virologic response, several previous studies reported that the baseline serum HBV DNA level in CHB patients who were resistant to antiviral therapy significantly influenced the achievement of virologic response when receiving TDF mono-rescue therapy. ${ }^{36}$ Lo et al. ${ }^{37}$ reported that patients with HBV DNA $<20,000 \mathrm{IU} / \mathrm{mL}$ had higher virologic response than those with $\mathrm{HBV}$ DNA $\geq 20,000 \mathrm{IU} / \mathrm{mL}$.

Renal safety is one of the greatest concerns with respect to the long-term administration of TDF in CHB patients. Because TDF is eliminated through urine by the kidneys, decreased renal function may interfere with the treatment response, resulting in a worsening of renal function. ${ }^{38}$ There are some reports of Fanconi syndrome mainly in the case of long-term use. AASLD suggests no particular preference between ETV and TDF regarding the potential long-term risks of renal and bone complications. $^{39}$ According to the 2017 EASL guidelines, one of the risk factors of renal safety is eGFR $<60 \mathrm{~mL} / \mathrm{min} / 1.73 \mathrm{~m}^{2}$. Careful use of TDF should be considered when patients possess other risk factors of renal dysfunction. The EASL guidelines also recommend the use of tenofovir alafenamide fumarate (TAF) as a switching therapy. ${ }^{4}$ Dose of TDF should be adjusted in accordance with renal function and the dose adjustments are required in case of eGFR $<50 \mathrm{~mL} / \mathrm{min} / 1.73 \mathrm{~m}^{2}$. When initiating TDF, risk assessment for renal dysfunction is recommended with close monitoring of renal function annually.
In the present study, TDF monotherapy or TDF-based combination therapy was shown to be relatively well tolerated. No serious adverse events were noted, and no discontinuation of the drug occurred due to nephrotoxicity. Some previous studies reported that older age, pre-existing renal insufficiency, prior long-term use of ADV, hypertension, and DM are associated with renal dysfunction. ${ }^{40-42}$ Although such parameters were not statistically significant for predicting renal impairment in this study, we suggest the importance of close monitoring of GFR and tubular function, especially in patients with mildly decreased GFR (eGFR 60 to $89 \mathrm{~mL} / \mathrm{min} / 1.73 \mathrm{~m}^{2}$ ) as well as DM patients. On the other hand, TAF could represent a new therapeutic option for patients with high risk of renal dysfunction, including those with DM and initial eGFR of less than $90 \mathrm{~mL} /$ $\min / 1.73 \mathrm{~m}^{2}{ }^{43,44}$

There are several limitations to consider. First, this study was single-center cohort study and several factors relevant to the baseline characteristics were different between the treatmentnaïve and treatment experienced groups due to the retrospective nature of this study. Second, the follow-up duration of individuals was affected by the time of TDF initiation. Except those with follow-up loss, many of the enrolled patients who initiated the drug in the late period have censored data due to expiration of the observation period. Moreover, the distribution of time period patients enrolled may differ between the two groups regarding reimbursement policy. Third, our data did not consider the urinalysis results of patients, such as proteinuria or albuminuria, as an indicator of renal function. Underlying hypertension and osteopenia with bone mineral density before and after treatment were also not assessed. Finally, our strict inclusion criteria may have influenced the results. Although this study has these limitations, our data is promising because it is obtained from a real-life experience and supports the previous results of clinical trials.

In conclusion, TDF therapy for $\mathrm{CHB}$ patients is a strongly effective treatment option for achieving virologic response regardless of previous treatment experience, TDF combination therapy, and antiviral resistance. $\mathrm{HBeAg}$-positive at baseline and serum HBV DNA level $\geq 2,000 \mathrm{IU} / \mathrm{mL}$ at 12 months were independent factors associated with virologic response. The incidence of renal impairment during long-term TDF therapy was relatively low among CHB patients with preserved GFR at baseline. However, the presence of DM and initial mildly decreased GFR (eGFR 60 to $89 \mathrm{~mL} / \mathrm{min} / 1.73 \mathrm{~m}^{2}$ ) may increase the risk of renal toxicity.

\section{CONFLICTS OF INTEREST}

No potential conflict of interest relevant to this article was reported. 


\section{ACKNOWLEDGEMENTS}

This study was supported by Fund of Biomedical Research Institute, Chonbuk National University Hospital.

\section{REFERENCES}

1. Korean Association for the Study of the Liver. KASL clinical practice guidelines: management of chronic hepatitis B. Clin Mol Hepatol 2016;22:18-75.

2. Dienstag JL. Benefits and risks of nucleoside analog therapy for hepatitis B. Hepatology 2009;49(5 Suppl):S112-S121.

3. Ghany MG, Doo EC. Antiviral resistance and hepatitis B therapy. Hepatology 2009;49(5 Suppl):S174-S184.

4. European Association for the Study of the Liver. EASL 2017 Clinical Practice Guidelines on the management of hepatitis B virus infection. J Hepatol 2017;67:370-398.

5. Tenney DJ, Rose RE, Baldick CJ, et al. Two-year assessment of entecavir resistance in Lamivudine-refractory hepatitis B virus patients reveals different clinical outcomes depending on the resistance substitutions present. Antimicrob Agents Chemother 2007;51:902-911.

6. Tenney DJ, Rose RE, Baldick CJ, et al. Long-term monitoring shows hepatitis B virus resistance to entecavir in nucleosidenaïve patients is rare through 5 years of therapy. Hepatology 2009;49:1503-1514.

7. Kayaaslan B, Guner R. Adverse effects of oral antiviral therapy in chronic hepatitis B. World J Hepatol 2017;9:227-241.

8. Zoulim F, Locarnini S. Management of treatment failure in chronic hepatitis B. J Hepatol 2012;56 Suppl 1:S112-S122.

9. Duarte-Rojo A, Heathcote EJ. Efficacy and safety of tenofovir disoproxil fumarate in patients with chronic hepatitis B. Therap Adv Gastroenterol 2010;3:107-119.

10. Woo G, Tomlinson G, Nishikawa Y, et al. Tenofovir and entecavir are the most effective antiviral agents for chronic hepatitis B: a systematic review and Bayesian meta-analyses. Gastroenterology 2010;139:1218-1229.

11. Marcellin P, Gane E, Buti M, et al. Regression of cirrhosis during treatment with tenofovir disoproxil fumarate for chronic hepatitis B: a 5-year open-label follow-up study. Lancet 2013;381:468-475.

12. Corsa AC, Liu Y, Flaherty JF, et al. No resistance to tenofovir disoproxil fumarate through 96 weeks of treatment in patients with lamivudine-resistant chronic hepatitis B. Clin Gastroenterol Hepatol 2014;12:2106-2112.e1

13. Buti M, Tsai N, Petersen J, et al. Seven-year efficacy and safety of treatment with tenofovir disoproxil fumarate for chronic hepatitis B virus infection. Dig Dis Sci 2015;60:1457-1464.

14. Berg T, Zoulim F, Moeller B, et al. Long-term efficacy and safety of emtricitabine plus tenofovir DF vs. tenofovir DF monotherapy in adefovir-experienced chronic hepatitis B patients. J Hepatol 2014;60:715-722.

15. Berg T, Marcellin P, Zoulim F, et al. Tenofovir is effective alone or with emtricitabine in adefovir-treated patients with chronichepatitis B virus infection. Gastroenterology 2010;139:1207-1217.

16. Lim YS, Yoo BC, Byun KS, et al. Tenofovir monotherapy versus tenofovir and entecavir combination therapy in adefovir-resistant chronic hepatitis B patients with multiple drug failure: results of a randomised trial. Gut 2016;65:1042-1051.

17. Fung S, Kwan P, Fabri M, et al. Randomized comparison of tenofovir disoproxil fumarate vs emtricitabine and tenofovir disoproxil fumarate in patients with lamivudine-resistant chronic hepatitis B. Gastroenterology 2014;146:980-988.

18. Cho HJ, Kim SS, Shin SJ, Yoo BM, Cho SW, Cheong JY. Tenofovir-based rescue therapy in chronic hepatitis B patients with suboptimal responses to adefovir with prior lamivudine resistance. J Med Virol 2015;87:1532-1538.

19. Ahn HJ, Song MJ, Jang JW, Bae SH, Choi JY, Yoon SK. Treatment efficacy and safety of tenofovir-based therapy in chronic hepatitis B: a real life cohort study in Korea. PLoS One 2017;12:e0170362.

20. Lovett GC, Nguyen T, Iser DM, et al. Efficacy and safety of tenofovir in chronic hepatitis B: Australian real world experience. World J Hepatol 2017;9:48-56.

21. Marcellin P, Zoulim F, Hézode C, et al. Effectiveness and safety of tenofovir disoproxil fumarate in chronic hepatitis B: a 3-year, prospective, real-world study in France. Dig Dis Sci 2016;61:30723083.

22. Petersen J, Heyne R, Mauss S, et al. Effectiveness and safety of tenofovir disoproxil fumarate in chronic hepatitis B: a 3-year prospective field practice study in Germany. Dig Dis Sci 2016;61:3061-3071.

23. Riveiro-Barciela M, Tabernero D, Calleja JL, et al. Effectiveness and safety of entecavir or tenofovir in a Spanish cohort of chronic hepatitis B patients: validation of the Page-B score to predict hepatocellular carcinoma. Dig Dis Sci 2017;62:784-793.

24. Levey AS, Bosch JP, Lewis JB, Greene T, Rogers N, Roth D. A more accurate method to estimate glomerular filtration rate from serum creatinine: a new prediction equation. Modification of Diet in Renal Disease Study Group. Ann Intern Med 1999;130:461470

25. Lee JM, Park JW, Choi BI. 2014 KLCSG-NCC Korea Practice Guidelines for the management of hepatocellular carcinoma: HCC diagnostic algorithm. Dig Dis 2014;32:764-777.

26. Marcellin P, Heathcote EJ, Buti M, et al. Tenofovir disoproxil fumarate versus adefovir dipivoxil for chronic hepatitis B. N Engl J Med 2008;359:2442-2455.

27. Liu Y, Corsa AC, Buti M, et al. No detectable resistance to tenofovir disoproxil fumarate in $\mathrm{HBeAg}+$ and $\mathrm{HBeAg}$ - patients with chronic hepatitis B after 8 years of treatment. J Viral Hepat 2017;24:6874.

28. Chung GE, Cho EJ, Lee JH, et al. Tenofovir has inferior efficacy in adefovir-experienced chronic hepatitis B patients compared to nucleos(t)ide-naïve patients. Clin Mol Hepatol 2017;23:66-73.

29. Yang DH, Xie YJ, Zhao NF, Pan HY, Li MW, Huang HJ. Tenofovir disoproxil fumarate is superior to lamivudine plus adefovir in 
lamivudine-resistant chronic hepatitis B patients. World J Gastroenterol 2015;21:2746-2753.

30. Lee SH, Cheon GJ, Kim HS, et al. Tenofovir disoproxil fumarate monotherapy is superior to entecavir-adefovir combination therapy in patients with suboptimal response to lamivudine-adefovir therapy for nucleoside-resistant HBV: a 96-week prospective multicentre trial. Antivir Ther 2018;23:219-227.

31. Wang H, Lu X, Yang X, Ning Q. Comparison of the efficacy of tenofovir monotherapy versus tenofovir-based combination therapy in adefovir-experienced chronic hepatitis B patients: a systematic review and meta-analysis. Int J Clin Exp Med 2015;8:2011120122.

32. Zoulim F, Białkowska-Warzecha J, Diculescu MM, et al. Entecavir plus tenofovir combination therapy for chronic hepatitis B in patients with previous nucleos(t)ide treatment failure. Hepatol Int 2016;10:779-788.

33. Gordon SC, Krastev Z, Horban A, et al. Efficacy of tenofovir disoproxil fumarate at 240 weeks in patients with chronic hepatitis B with high baseline viral load. Hepatology 2013;58:505-513.

34. Kitrinos KM, Corsa A, Liu Y, et al. No detectable resistance to tenofovir disoproxil fumarate after 6 years of therapy in patients with chronic hepatitis B. Hepatology 2014;59:434-442.

35. Snow-Lampart A, Chappell B, Curtis M, et al. No resistance to tenofovir disoproxil fumarate detected after up to 144 weeks of therapy in patients monoinfected with chronic hepatitis B virus. Hepatology 2011;53:763-773.

36. Lee S, Park JY, Kim DY, et al. Prediction of virologic response to tenofovir mono-rescue therapy for multidrug resistant chronic hepatitis B. J Med Virol 2016;88:1027-1034.
37. Lo A0, Wong VW, Wong GL, Tse YK, Chan HY, Chan HL. Efficacy of tenofovir switch therapy for nucleos(t)ide-experienced patients with chronic hepatitis B. Aliment Pharmacol Ther 2015;41:11901199.

38. Coppolino G, Simeoni M, Summaria C, et al. The case of chronic hepatitis B treatment with tenofovir: an update for nephrologists. J Nephrol 2015;28:393-402.

39. Terrault NA, Bzowej NH, Chang KM, et al. AASLD guidelines for treatment of chronic hepatitis B. Hepatology 2016;63:261-283.

40. Jung WJ, Jang JY, Park WY, et al. Effect of tenofovir on renal function in patients with chronic hepatitis B. Medicine (Baltimore) 2018;97:e9756.

41. Wang HM, Hung CH, Lee CM, et al. Three-year efficacy and safety of tenofovir in nucleos(t)ide analog-naïve and nucleos(t)ide analog-experienced chronic hepatitis B patients. J Gastroenterol Hepatol 2016;31:1307-1314.

42. Lampertico P, Chan HL, Janssen HL, Strasser SI, Schindler R, Berg T. Review article: long-term safety of nucleoside and nucleotide analogues in HBV-monoinfected patients. Aliment Pharmacol Ther 2016;44:16-34.

43. Buti M, Gane E, Seto WK, et al. Tenofovir alafenamide versus tenofovir disoproxil fumarate for the treatment of patients with HBeAg-negative chronic hepatitis B virus infection: a randomised, double-blind, phase 3, non-inferiority trial. Lancet Gastroenterol Hepatol 2016;1:196-206.

44. Buti M, Riveiro-Barciela M, Esteban R. Long-term safety and efficacy of nucleo(t)side analogue therapy in hepatitis B. Liver Int 2018;38 Suppl 1:84-89. 